\title{
Development and characterization of liposomal formulation containing phytosterols and tocopherols with the aim of reducing low-density lipoprotein cholesterol
}

Asmita Poudel ${ }^{1}$, George Gachumi ${ }^{1}$, Zafer Dallal Bashi ${ }^{1}$, Ildiko Badea ${ }^{1}$ and Anas El-Aneed $^{1}$

${ }^{1}$ College of Pharmacy and Nutrition, University of Saskatchewan, Saskatoon, Saskatchewan

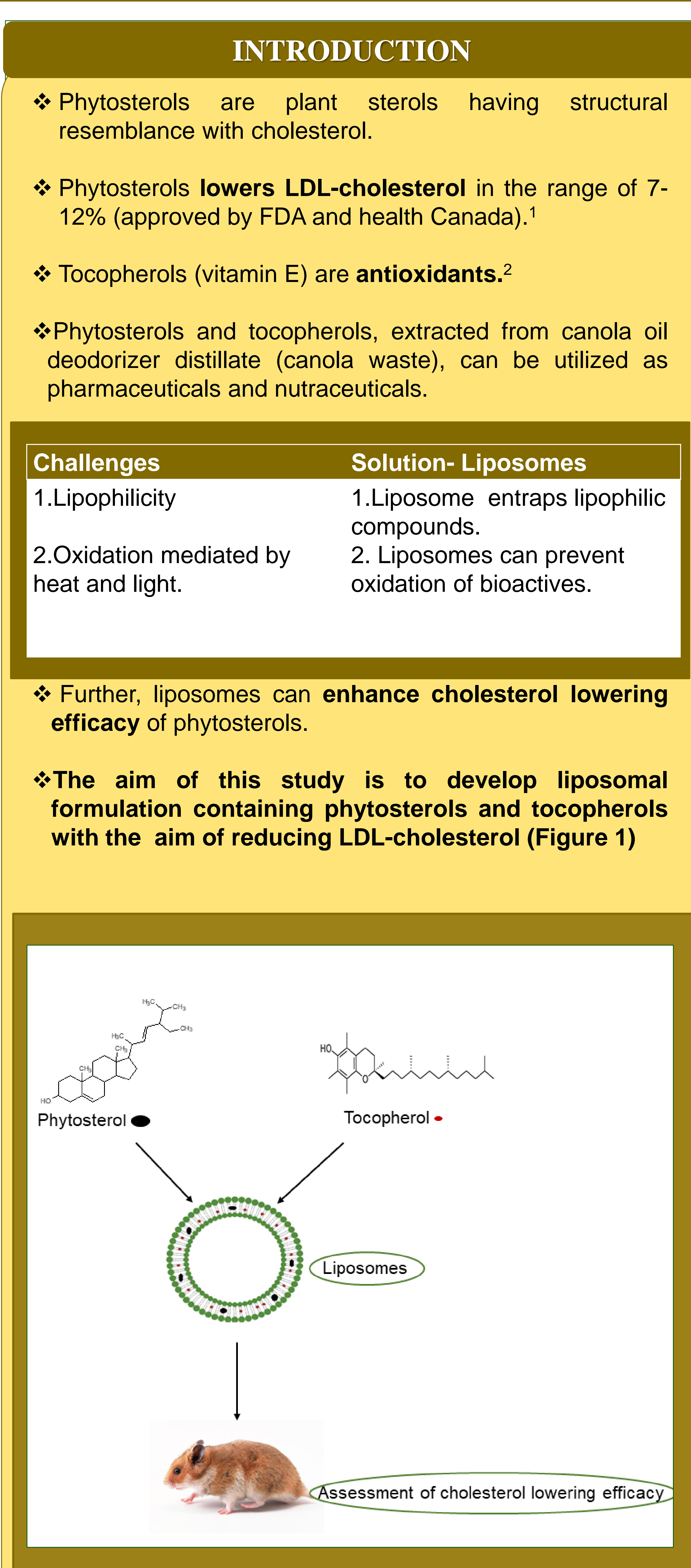

Figure 1: Research summary showing liposomal formulation of phytosterols and tocopherols. Cholesterol lowering efficacy will be assessed in animal model.

\section{HYPOTHESES AND OBJECTIVES}

\section{Hypothesis I}

Phytosterols and tocopherols extracted from canola oil deodorizer distillate can be entrapped at high efficiency (above $90 \%$ ) using optimized liposomal formulation comprised of soy phosphatidylcholine.

Objective 1: To formulate liposomes containing phytosterols and tocopherols using- thin layer hydration homogenization, thin

Objective 2: To develop and validate liquid chromatography tandem mass spectrometry ( LC-MS/MS) method for comparative evaluation of the entrapment efficiency of liposomes prepared by the above-mentioned techniques.

\begin{tabular}{|c|c|c|c|c|}
\hline MATERIALS AND METHOD & \multicolumn{4}{|c|}{ RESULTS AND DISCUSSIONS } \\
\hline 1. Formulation of liposomes & \multirow{6}{*}{\multicolumn{4}{|c|}{$\begin{array}{l}\text { 1.Particle size and zeta potential } \\
\text { The particle size was significantly larger when employing the } \\
\text { Mozafari method }(260 \mathrm{~nm}) \text { compared to homogenization } \\
(186 \mathrm{~nm}) \text { and ultrasonication (196 } \mathrm{nm}) \text { methods. Whereas } \\
\text { zeta potential was comparable among all three formulations } \\
(-14 \mathrm{mV} \text { to }-9 \mathrm{mV}) \text { as shown in Table } 1 \text {. Polydispersibility } \\
\text { index (PDI) was in the range of } 0.29-0.37 \text {. All of these values } \\
\text { are adequate for colloidal stability. } \\
\text { Table 1: Particle size }(\mathrm{nm}) \text {, Zeta potential ( } \mathrm{mV}) \text {, and } \\
\text { polydispersibility index (PDI) of liposomes prepared using } \\
\text { homogenization, ultrasonication, and Mozafari methods } \\
\text { expressed as mean } \pm \text { standard deviation where * represents } \\
\text { statistical significance }(\mathrm{p}<0.05) \text {. }\end{array}$}} \\
\hline & & & & \\
\hline i) Thin laver hvdration Homogenization 3 & & & & \\
\hline ii) Thin layer hydration Ultrasonication ${ }^{4}$ & & & & \\
\hline iii) Mozafari method ${ }^{5}$ & & & & \\
\hline $\begin{array}{l}* \text { Phosphatidylcholine }(\mathrm{PC}) \text { was utilized in all three methods } \\
\text { and the utilized phase transition temperature was } 55^{\circ} \mathrm{C} \text {. }\end{array}$ & & & & \\
\hline \multirow[t]{2}{*}{ using Malvern zeta sizer. } & $\begin{array}{l}\text { Formulation } \\
\text { techniques }\end{array}$ & $\begin{array}{l}\text { Average } \\
\text { particle } \\
\text { size }(\mathrm{nm})\end{array}$ & PDI & $\begin{array}{l}\text { Zeta } \\
\text { potential } \\
(\mathrm{mV})\end{array}$ \\
\hline & Homogenization & $186.3 \pm 4.4$ & $0.370 \pm 0.001$ & $-13.0 \pm 5.0$ \\
\hline \multirow[t]{2}{*}{ 2. Development and validation of LC-MS/MS method } & & & & \\
\hline & Ultrasonication & $196.2 \pm 16.1$ & $0.294 \pm 0.084$ & $-14.0 \pm 3.4$ \\
\hline MS and LC conditions & Mozafari method & $260.0 \pm 23.0^{*}$ & $0.348 \pm 0.087$ & $-9.8 \pm 0.3$ \\
\hline
\end{tabular}

AB Sciex quadrupole linear ion trap (QTRAP 6500) with APCI positive mode was used (figure 2).

- UPLC system was Agilent binary pump, Agilent 1290 infinity.

Agilent Poroshell, C18 column $2.1 \mathrm{~mm} \times 150 \mathrm{~mm}, 5 \mu \mathrm{m}$ was utilized.

- Elution was isocratic with Acetonitrile (0.1\%Acetic acid) and methanol $(0.1 \%$ Acetic acid) at $99: 1$ ratio

- Method validation was done as per International council for Harmonization (ICH) guidelines ${ }^{6}$

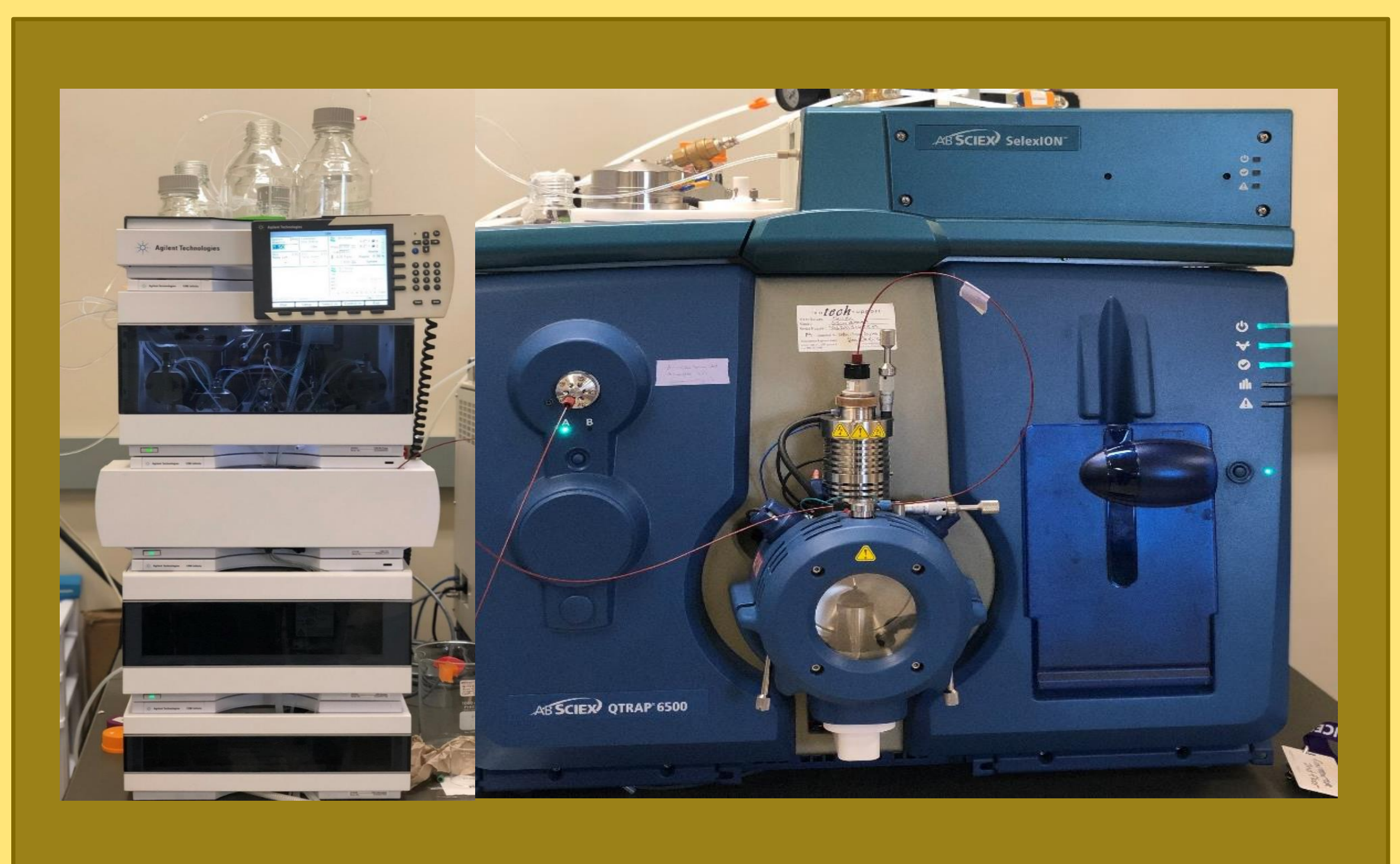

Figure 2. Liquid chromatographic system coupled with mass spectrometer $\star$ Following validation parameters were assessed:

a. Linearity

b. Sensitivity

c. Accuracy and

e. Dilution integrity

f. Stability

All of these parameters met the $\mathrm{ICH}$ acceptance criteria.

\section{Entrapment efficiency}

All three methods showed the intended entrapment efficiency that was greater than $89 \%$ as shown in table 3 .

Table 3: Entrapment efficiency of liposomal phytosterols and tocopherols formulated using homogenization, ultrasonication, and Mozafari methods expressed as mean \pm deviation.

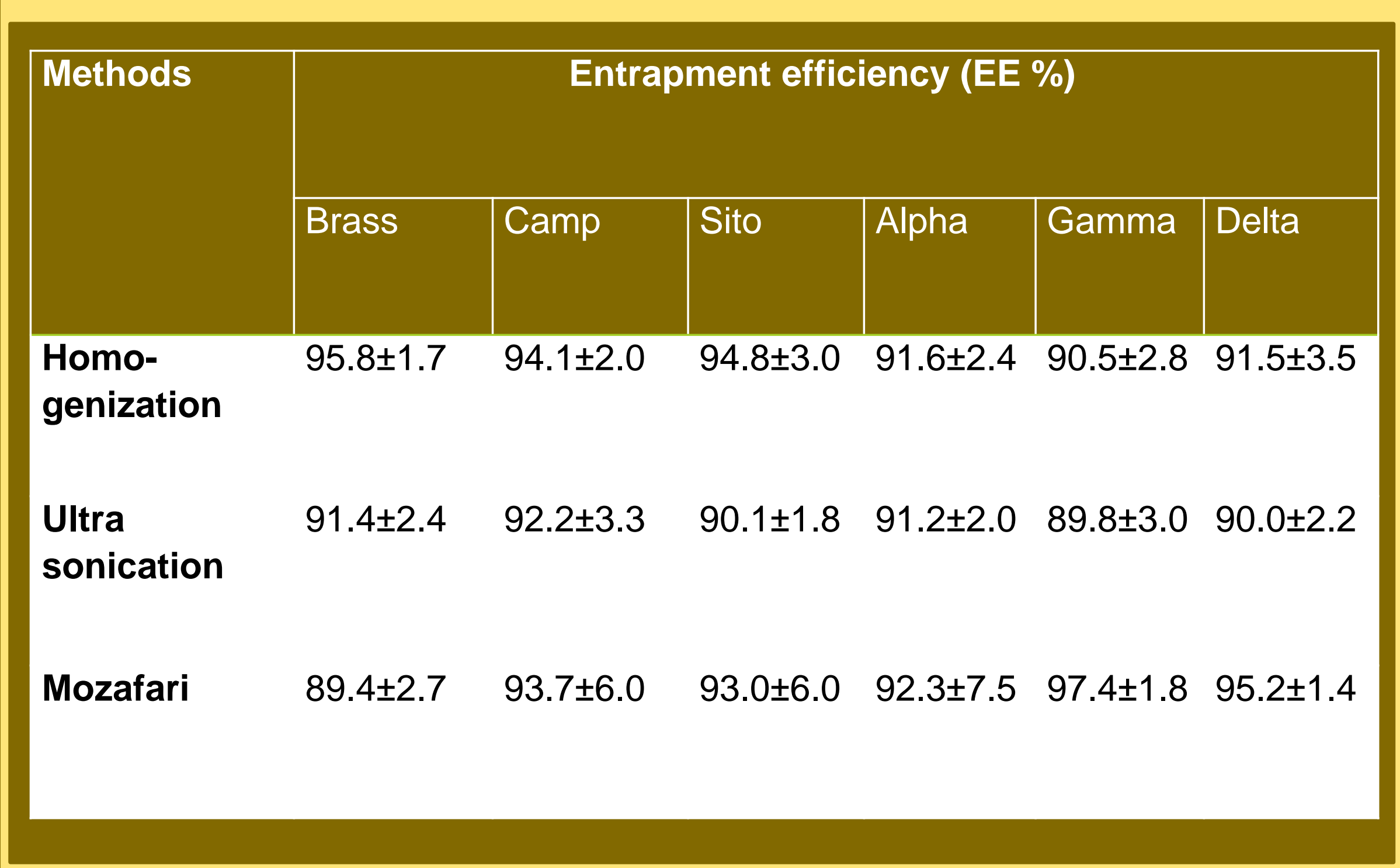

LC-MS/MS method was successfully developed and validated a per ICH guideline ( the chromatogram is

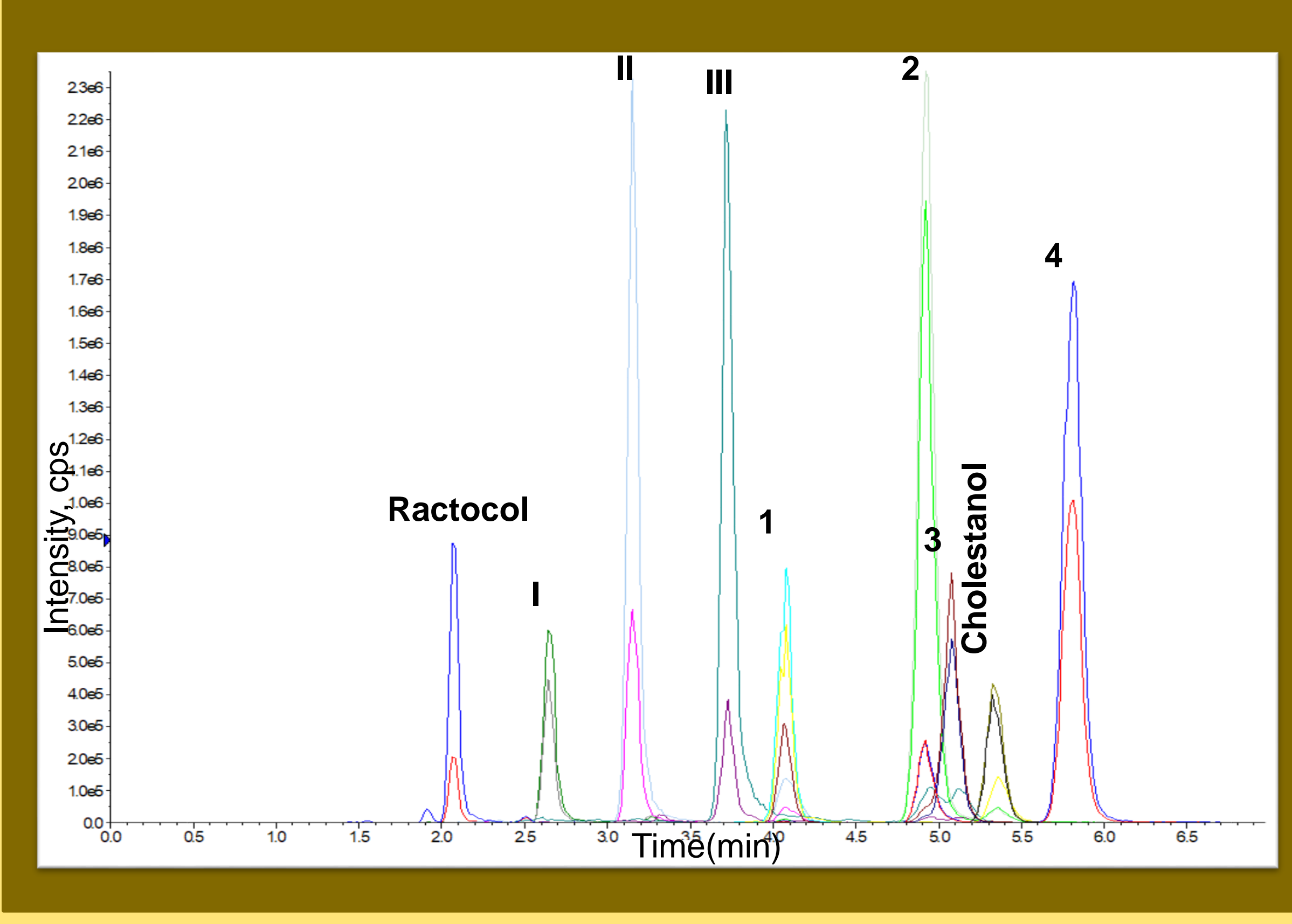

Figure 3. LC-MS/MS spectra of phytosterols and tocopherols. 1-brassicasterol, 2-campesterol, 3-stigmasterol, 4- $\beta$-sitosterol, I- $\delta, ~ I I-~ \beta / y, ~ I I I-\alpha$ tocopherols. Cholestanol and ractocol were used as internal standard for phytosterols and tocopherol respectively.

\section{Method Validation}

Table 2 : Linear range and sensitivity of phytosterols and tocopherols (LLOQ represents lower limit of quantitation
and LOD represents limit of detection).

\begin{tabular}{|cccc|}
\hline $\begin{array}{c}\text { Compound } \\
\text { name }\end{array}$ & $\begin{array}{c}\text { LLOQ } \\
(\mu \mathrm{g} / \mathrm{mL})\end{array}$ & $\begin{array}{c}\text { LOD } \\
(\mu \mathrm{gg} / \mathrm{mL})\end{array}$ & $\begin{array}{c}\text { Linear range } \\
(\mu \mathrm{g} / \mathrm{mL})\end{array}$ \\
Tocopherols & 0.25 & 0.01 & $0.25-10$ \\
Phytosterols & 0.05 & 0.005 & $0.05-10$ \\
\hline
\end{tabular}

CONCLUSIONS AND FUTURE WORK

* All three-formulation strategies showed size and zeta potential suitable for colloidal stability and oral delivery. * Robust analytical method was developed and validated. It was successfully applied to measure entrapment efficiency. $*$ Ongoing work is the assessment of cholesterol lowering efficacy of liposomal phytosterols in animal model.

\section{REFERENCES}

1. Ras et al. British Journal of Nutrition, 2014, 112, 214-219. 2. Tang et al. European Food Research and Technology, 2001 , 213, 286-289.

3.Chung et al. Colloid, 2014, 454, 8-15

4. Akbarzadeh et al. Nanoscale Res.Lett. 2013, 8, 1-9

5. Mozafari et al. Micron 2007, 38, 841-347

6. International council on Harmonization, 2005, 11-12

\section{ACKNOWLEDGEMIEN} formulation development.

The authors thank Dr. Ellen Wasan and Dr. Kishor Wasan or their valuable suggestions in this work.

The authors thank Ms. Deborah Michel for the training she provided in operating homogenizer and mass spectrometer.

I Government T.

Agriculture development fund (ADF)
The authors thank Dr. Amal Makhlouf for her help in 